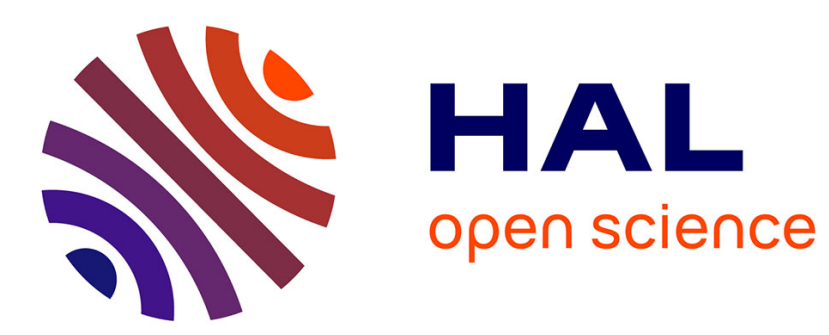

\title{
L'HÉRITABILITÉ DE LA PRODUCTION D'GUFS DOUBLES CHEZ LA POULE
}

P. Corcelle

\section{To cite this version:}

P. Corcelle. L'HÉRITABILITÉ DE LA PRODUCTION D'(EUFS DOUBLES CHEZ LA POULE. Annales de génétique et de sélection animale, 1969, 1 (2), pp.195-195. hal-00892356

\section{HAL Id: hal-00892356 https://hal.science/hal-00892356}

Submitted on 1 Jan 1969

HAL is a multi-disciplinary open access archive for the deposit and dissemination of scientific research documents, whether they are published or not. The documents may come from teaching and research institutions in France or abroad, or from public or private research centers.
L'archive ouverte pluridisciplinaire HAL, est destinée au dépôt et à la diffusion de documents scientifiques de niveau recherche, publiés ou non, émanant des établissements d'enseignement et de recherche français ou étrangers, des laboratoires publics ou privés. 
près équivalente dans les deux lignées. En présence des deux régimes, la croissance pondérale de la souche de Faverolles était supérieure à celle de la souche L22; à 43 jours, 645, 1 gramme contre 524,7 g pour les mâles, et $572,6 \mathrm{~g}$ contre $454,0 \mathrm{~g}$ pour les femelles dans le lot témoin. Dans les deux sexes, le retard de croissance du lot carencé par rapport au témoin se manifeste un peu plus tôt pour les animaux "L22 "que pour les Faverolles.

\section{L'HÉRITABILITÉ DE LA PRODUCTION D'GUUS DOUBLES CHEZ LA POULE}

P. Corceit,E. - S.A. Studler. - Élevage des Godards, 22-L'Hermitage-Lorge

Nous avons étudié sur 2 populations de Plymouth Rock blanches génétiquement différentes la production d'œufs à double jaune au cours d'une période de contrôle de ponte de 4 mois. L'identification de ces œufs était basée seulement sur leur aspect. En 1964, sur la descendance de 47 parquets pedigree analysée pour ce caractère, l'héritabilité estimée à partir de la composante "père " de la variance valait 0,32 , celle estimée à partir de la composante " mère " 0,07 , d'où une valeur moyenne égale à 0,20 . En 1966, une autre population, étudiée sur la descendance de 10 parquets pedigree, a révélé une héritabilité plus élevée : 0,57 à partir de la composante "père ", 0,27 à partir de la composante "mère ", la moyenne des 2 atteignant 0,42 . Dans les 2 cas, la valeur plus grande de la composante "père "indique une liaison probable au sexe.

D'autre part, cette dernière population a été divisée en 2 parties, l'une provenant de familles dont aucune poule n'avait produit d'œufs doubles, l'autre issue des familles ayant donné au maximum de tels œufs. A la génération suivante, la proportion des oufs à 2 jaunes sur l'ensemble de la période contrôlée était de 13 p. 1000 dans le premier cas, et de 57 p. 1000 dans le deuxième.

\section{VARIABILITÉ GÉNÉTIQUE DU POURCENTAGE DE PEAU CHEZ LE POULET}

F.-H. RICARD. - Station expérimentale d'Aviculture du Magneraud, I7-St-Pierre-d'Amilly.

Le pourcentage de peau de la carcasse éviscérée a été déterminé sur plusieurs groupes de poulets mâles âgés de 11 semaines, pour voir s'il existait une variation de type génétique. Dans une première série d'expériences, nous avons étudié 4 échantillons correspondant à 4 souches de type different, chacun d'eux étant comparé à un échantillon de poulets Bresse-pile, souche maintenue sans sélection qui servait de témoin. L'effectif était de 30 animaux par groupe. Si on donne la valeur 100 à la moyenne des poulets Bresse-pile, on obtient 110 pour une souche de type Wyandotte, 106 pour une souche de type Rhode-Island, 97 pour une souche de type Sussex (la différence n'étant pas significative) et 91 pour une souche de type Cornish. Une autre expérience a permis d'étudier 315 coquelets appartenant tous à la souche Bresse-pile, fils de 8 coqs et de 32 poules. L'analyse hiérarchique des variances a fait apparaitre des différences significatives aussi bien entre familles de mères qu'entre familles de pères. La composante mère de l'héritabilité était de 0,40 et la composante père de 0,90 .

Les relations entre le pourcentage de la peau et sa finesse restent à préciser. Mais pour ce pourcentage, qui mesure l'importance relative de la peau, nous avons pu mettre en évidence des différences entre souches et entre familles d'une même souche. Il semble donc possible de tenir compte de ce caractère dans les programmes de sélection, par exemple à partir de tests sur collatéraux ou sur descendance. 